\title{
UN ALCALDE DE BARRIO EN EL MADRID DE CARLOS IV *
}

El gobierno político de una gran urbe, como Madrid, necesariamente ha de producir notables quebraderos de cabeza a quien se responsabilice de encargo tan comprometedor. Hoy, como ayer, el mantenimiento del orden público y la paz ciudadana es tarea nada envidiable, en la que difícilmente se acierta por completo. Aunque pueda producirnos un gesto de extrañeza la comparación entre la macrópolis actual y el Madrid dieciochesco, lo cierto es que en aquella época la Villa y Corte, con ciento cuarenta mil habitantes al comenzar el siglo, era la ciudad más populosa de España, con medios infinitamente menores que los de hoy.

Por otra parte, a gran distancia de las demás cortes europeas, Madrid era una villa de pobre aspecto, sucia y maloliente, que luchaba por sobrevivir entre fuertes contrastes sociales: grandes fortunas al lado de incontables mendigos, habituados a la ociosidad y a la limosna. Valga como ejemplo un dato escueto: la Hermandad del Refugio y de la Piedad, desde su fundación en 1618 hasta el año 1800, había socorrido a un millón de pobres. Es decir, un promedio de quinientas mil personas en cada centuria. Si a la pobreza añadimos la enfermedad, con las diez mil personas enfermas atendidas anualmente sólo en los hospitales General y de la Pasión (de los dieciocho con que contaba la Villa) nos daremos una somera idea de los graves problemas sociales que agobiaban a la capital de España en el refinado siglo de los abates y de las pelucas.

El urbanismo, en su conjunto, era el propio de una villa castellana con escasa tradición nobiliaria. Bien sabido es que sus edificios monumentales,

* Conferencia pronunoiada en el Centro Cultural de la Villa de Madrid el día 9 de febrero de 1978. 
iglesias y conventos eran inferiores en calidad e importancia a los de otras ciudades españolas. Ciertamente, las casas palaciegas iban aumentando a lo largo del siglo, pero a su lado se veían humildes viviendas y malolientes tabernas o talleres de artesanos, por carecer de ordenanzas que regulasen la construcción ${ }^{1}$. En sus seis kilómetros cuadrados de superficie se apiñaban las casas de vecinos, los corrales, los cuartos y buhardillas, donde el espacio vital quedaba reducido al mínimo, junto a los amplios conventos ${ }^{2}$, las casas nobiliarias y los grandes edificios públicos. La propiedad urbana estaba concentrada en muy pocas manos, de forma que el acceso a una vivienda era posible sólo mediante el arriendo y el subarriendo. Las rentas urbanas eran uno de los principales ingresos de las comunidades religiosas ${ }^{3}$, las hermandades pías y los nobles, cuyo número excedía a los comerciantes en razón de cuatro a uno.

Desde aquí os invito a visitar y contemplar la maravillosa maqueta de Madrid que se muestra al público en el Museo municipal y que ningún madrileño debe desconocer. Nada nos acerca tanto al siglo XVIII de la Villa y Corte como esta impar obra de arte, realizada en 1830 por el Teniente Coronel de Artillería don León Gil del Palacio. La maqueta de Cádiz, construida por deseo de Carlos III, que se conserva en el museo ga-

1 El caos de la construcción en el Madrid del siglo XVIII queda atestiguado en el siguiente párrafo del marqués de Uztariz: «En Madrid cada uno labra a su genio y a su gusto, sin la menor atención a la hermosura del Pueblo, y sin que la justicia pueda irla a la mano, por falta de ordenanzas que establezcan el modo. Una prueba bien visible nos da la calle Mayor. En ella se ha fabricado últimamente una casa de tan extraordinaria elevación que descuella excesivamente sobre las demás. Púsose pleito al dueño y el Consejo determinó justamente a su favor, porque no habiendo Establecimiento alguno que dirija las medidas y altura de estas obras, queda a la libre elección de cada uno el fabricar a su genio y modo (Discurso sobre el gobienno de Madrid. 1746. Manuscrito 7.049, fol. 22, en la Biblioteca Nacional de Madrid).

2 La cifra de 36 conventos de frailes y 31 de monjas que da el manuscrito 6.966 de la Biblioteca Nacional, difiere de la citada por F. Jiménez de Gregorio en su artículo "La población de la Villa de Madrid en el censo de Aranda" (Anales del Instituto de Estudios Madrileños, III, 1968, p. 173) donde da también la cantidad de 117.274 habitantes en el Madrid de 1768.

3 En 1705, «habiéndose hecho el cómputo de las casas de Madrid para cobrar un impuesto, se halló haber en Madrid 23.000 casas, y de éstas 17.000 de frailes. Sólo el Colegio Imperial era propietario de 1.186 y las demás Comunidades de la Compañia otras 1.600" (Biblioteca Nacional, Mss. 18.447, fol. 269). Sería de sumo interés un estudio sobre la propiedad urbana en Madrid, tomando como base los datos aportados por los tomos de la Planimetria de Madrid (1768). 
ditano, es anterior a ésta y de mayor proporción, dada la diferencia del vecindario de las dos poblaciones. Pero la de Madrid la supera en minuciosidad y detallismo. Es una miniatura de sorprendente exactitud y realismo, además de incalculable valor histórico y artístico. Apretada la Villa entre el Palacio Real y los jardines del Buen Retiro, el caserío está estructurado en forma radial, con crecimiento anárquico a partir del centro urbano, marcado por la Puerta del Sol, y un eje transversal formado por las calles Mayor y Alcalá.

Aunque realizada en 1830 , la maqueta puede servirnos perfectamente para el estudio del Madrid dieciochesco, ya que las reformas realizadas hasta ese momento fueron mínimas, en su mayor parte debidas a José Bonaparte. Basta imaginar, en su lugar correspondiente, las iglesias desaparecidas (Santa Ana, San Miguel, San Ildefonso, Santa Catalina, San Martín, Santa Bárbara, los Mostenses, etc.) y el gran espacio de la nueva Plaza de Oriente, delante del Palacio Real, donde antes estaban ubicadas la Biblioteca Real y el teatra de los Caños.

Así, a vista de pájaro, Madrid era una ciudad poco apta para la convivencia. Si exceptuamos el Paseo del Prado, ampliado y exornado por Carlos III, y el parque deI Buen Retiro, abierto sólo parcialmente al público a finales de siglo, ni un solo árbol en el casco urbano, a no ser en jardines privados. Pocos espacios abiertos, calles estrechas y plazuelas de escasas dimensiones. El gran centro de convivencia era, sin duda, la Plaza Mayor, muy diferente a como hoy la conocemos, a causa del incendio que la destruyó, aunque no en su totalidad, en 1790. En estas condiciones no es extraño que el orden público se viese alterado con frecuencia. De pequeñas proporciones con motivo de disputas particulares y querellas callejeras. Pero de mayor alcance cuando el motivo eran las crisis de abastecimiento, tan frecuentes en el siglo.

La historia de la organización municipal madrileña es tema que espera aún al investigador que la estudie en su conjunto. Desde luego, la mayor complejidad reside en la dual jurisdicción que es característica de la Villa y Corte. En tiempos de San Fernando ya existían los alcaldes del Rey, pero fueron los Reyes Católicos quienes, en las cortes de Toledo de 1480, aprobaron la existencia de cuatro alcaldes que sentenciasen las causas criminales y civiles de la corte, y que la seguian, por tanto, en sus diferentes traslados. Con Felipe II, instalada ya la corte en Madrid, el número de alcaldes asciende a seis, pero es Felipe III el que, por una pragmática de 1599 , reglamenta sus horas y días de audiencia en la villa madrileña, que 
vuelve a acoger a los alcaldes cortesanos, tras el breve paréntesis de Valladolid como capital de España ${ }^{4}$.

Paralelamente, la jurisdicción municipal estaba reglamentada por las primeras ordenanzas, que datan de 1585. Esta situación permanece invariable hasta el 10 de noviembre de 1713 , en que Felipe $V$ firma el decreto de Nueva Planta. Treinta años después la Sala de Alcaldes de la Casa y Corte se componía de doce jueces, nombrados por el Rey y presididos por un consejero de Castilla. E1 jefe de la policía madrileña era el alguacil mayor, asistido por cuarenta alguaciles y veinticuatro porteros de vara, con atribuciones civiles y criminales. Su jurisdicción se extendía a cinco leguas alrededor de Madrid ${ }^{5}$.

Apenas llegado Carlos III a la capital de España, comenzaron las regias disposiciones para transformar el aspecto descuidado de la corte. Aun antes de hacer su entrada oficial en Madrid, el 3 de julio de 1760 , ya dictó el nuevo Rey varias órdenes sobre el vestido que debían usar los funcionarios, ministros de los tribunales y oficiales de las Reales tropas ${ }^{6} \mathrm{Al}$ año siguiente, aprueba el proyecto de Sabatini para modernizar el empedrado de las calles, sustituyendo los molestos guijarros por "baldosas de pie quadrado, piedra berroqueña, rayadas en cuadros pequeños para comodidad de los coches y gente de a pie, en la forma que están las del patio, pórtico y entrada del Palacio Mayor». La Carrera de San Jerónimo fue la elegida para iniciar las obras ${ }^{7}$. Al mismo tiempo, a propuesta del propio Sabatini, se dictan las (reglas que deberán observarse para construir las cloacas, vertederos y conductos de aguas mayores y menores $)^{8}$. Este proyecto requeria la construcción de "pozos negros» en lugares estratégicos, idea ya apuntada por Antonio Ulloa en 1750. La actividad de estos años fue tan intensa que,

4 La obligación de los Alcaldes del Rey era acompañar a éste en todos sus viajes y asegurar la policía y abasto de su residencia, juzgando los asuntos criminales de la Corte y su Rastro, y los civiles de cierta entidad... hasta ser un tribunal especial, presidido por un Consejero de Castilla, con el título de Gobernador de Sala y un número de alcaldes variable». (A. González Palencia, Introducción histórica al Catálogo de la Sala de Alcaldes de Casa y Corte. Madrid, 1925).

5 G. Desdevises du Dezert, «La Chambre des Juges de l'Hotel et de la Cour en 1745). (En Revue Hispanique, XXXVI, 1916, pp. 1-51).

6 A. Ferrer del Río, Historia del reinado de Carlos III en España. Tomo I. Madrid, 1856 , p. 266.

7 Carmen Rubio Pardos, «La Carrera de San Jerónimo». (En Anales del Instituto de Estudios Madrileños, VII, 1971, p. 99).

8 AHN, Consejos, libro 1482, núm. 29. 
entre 1762 y 1765, se construyeron en Madrid 34.275 pozos, que habían die ser limpiados periódicamente ${ }^{9}$. La modernización del alumbrado nocturno, a costa de los vecinos, se reglamentó en abril de $1765^{10}$.

Bastarían, pues, los cinco primeros años del reinado de Carlos III para adjudicar a este monarca el calificativo de "mejor alcalde de Madrid», con que en justicia se le conoce. Pero aún quedaban otras medidas de carácter institucional que posiblemente no hubiese puesto en práctica sin un suceso de extraordinaria importancia social, que vino a sacudir violentamente el ánimo regio y a impulsar nuevas y más radicales reformas. Me refiero, naturalmente, al motín del pueblo madrileño que tuvo lugar en la Semana Santa de 1766, conocido vulgarmente como el "motín de Esquilache». En estos días, según el profesor Cepeda Adán, «las calles de Madrid son escenario de uno de los primeros hechos de masas de la historia european" . Alborotos callejeros los hubo siempre en Madrid, en especial durante la Guerra de Sucesión ${ }^{12}$, pero nunca, hasta entonces, llegaron a cimas tan

9 Esta actividad fue en progresión creciente, de forma que en 1762 se hicieron 2.279 pozos; en 1763, 6.156; en 1764, 12.811; en 1765, 13.029. (Véase al artículo de M. Gloria Sanz Sanjosé y José Patricio Merino Navarro, "Saneamiento y limpieza en Madrid. Siglo XVIII", en Anales del Instituto de Estudios Madrileños, XII, 1976, pp. 119-142). Sohre el anterior sistema de limpieza pública pueden consultarse los documentos conservados en el AHN (Consejos, leg. 17712) por Jos cuales nos enteramos de que los Cinco Gremios Mayores prestaban gruesas cantidades al Ayuntamiento de Madrid, con el interés del tres por ciento, para el pago de esta limpieza, realizada por "mangueros» de pala y escoba, que completaban la labor de Ios carros. Desde 1729 a 1744 se les abonaron 1.970 .918 reales por sus servicios.

10 A. González Palencia, "El alumbrado público en Madrid en el siglo XVIII». Ma. drid, 1928 y M. C. Simón Palmer, “Faroleros y serenos (Notas para su historia)», en Anales del Instituto de Estudios Madrileños, XII, 1976, pp. 183-204. En el año 1800 los 115 faroleros de Madrid encendian diariamente 4.600 faroles de velas de sebo.

11 José Cepeda Adán, «El Madrid de Carlos III en las cartas del marqués de San Leonardo», (En Anales del Instituto de Estudios Madrileños, I, 1966, pp. 219-230).

12 El 26 de marzo de 1704 «azotaron en Madrid a una mujer por aver perdido el respeto al Corregidor, sobre encarecerse el pan». En octubre del mismo año "padecíanse muchos hurtos en Madrid, y aviéndose maliciado en ciertos ministros, se descubrió que a catorce ministros $y$ otros se retiraron a sagrado o huyeron». Al mes siguiente hubo nuevos alborotos, a causa de la prisión del conde de Cifuentes. En abril de 1705 hubo los principales agresores eran alguaciles de la Corte y oficiales de la Sala... prendieron gran conmoción popular a causa de las constantes amenazas espirituales que dirigía a las prostitutas de la Puerta del Sol, las cuales, en unión del vecindario, lo molieron a palos. Estos y otros acontecimientos semejantes pueden leerse en el Mss. 18447 de la Biblioteca Nacional. 
altas de violencia, solidaridad popular y osadía en sus exigencias. Recordemos brevemente lo sucedido.

La tragedia comenzó a las seis de la tarde del Domingo de Ramos, 23 de marzo. El descontento del pueblo llano venía de meses atrás, a causa de la subida de los precios en los productos básicos de la alimentación. EI malestar subió de punto con la real orden que prohibía el uso de la capa tradicional y el sombrero gacho. Recortando las capas y subiendo las alas de los sombreros hasta formar un tricornio, se pretendía evitar el ocultamiento del rostro en la negra noche madrileña, tan propicia a crímenes y atentados.

No sospechaba, sin embargo, el Gobierno, las consecuencias de tan impopular medida. EI primer escenario de la conjuración fue la Plaza Mayor. En pocas horas se congregaron en ella más de seis mil hombres, excitados por la eficaz acción de los piquetes (que, como se ve, no es cosa de hoy). De allí marcharon a la casa de Esquilache, gritando hasta el Palacio Real, frente al que se apostaron — superando ya los quince mil manifestantescon voces de ¡Viva el Rey y muera Esquilache! De la refriega con las tropas resultaron muertos siete soldados walones y cuarenta manifestantes, entre ellos «algunas mujeres, que eran las peores, con sus banderas, tambores y palmas». Al día siguiente, en la Puerta del Sol resultaron muertos, a palos y pedradas, otros diez miembros de las tropas walonas, odiados por el pueblo, igual que el ministro, por su condición de extranjeros.

El Rey hubo de acceder a las peticiones de los amotinados, entre las que se contaba la baja de los precios y el destierro de Esquilache, pero, atemorizado ante la gravedad de la revuelta, se trasladó secretamente al palacio de Aranjuez, del que no regresó hasta pasados ocho meses. Hay que hacer resaltar que el motín no perseguía fines revolucionarios, puesto que los vivas al Rey fueron constantes, pero Carlos III, sintiéndose sin duda humillado al tener que condescender con las exigencias populares, concibió medidas extremas para salvaguardar la autoridad de la Monarquía y el orden público, alterado también en otras capitales ${ }^{13}$. Incluso pensó en trasladar la corte a Sevilla, pero fue disuadido de tal pensamiento y se limitó

13 Cesado el motín de Madrid, se produjeron otros en cadena: Barcelona, Zaragoza, Soria, Guadalajara, Toledo, Cuenca, Ciudad Real, Alicante, Granada, Jaén, Cádiz, Sevilla, Badajoz, Salamanca, Valladolid, Burgos, Palencia, Oviedo, Bilbao, La Coruña y otras poblaciones menores, hasta un total de 69. 
a depositar su confianza en el conde de Aranda, al que concedió plenos poderes, nombrándole presidente del Consejo de Castilla.

Los historiadores han detectado en el motín de 1766 algo más que una simple revuelta de protesta popular. Tras los amotinados, Ferrer del Río ve a la poderosa Compañía de Jesús, interesada en la caída de Esquilache y del confesor del Rey. El padre Eguía ve a los masones; Rodríguez Casado, a la nobleza y clases privilegiadas. Para Navarro Latorre fueron simplemente motivos económicos, lo mismo que para el francés Pierre Vilar. Corona Baratech lo achaca a la impopularidad de las reformas. Finalmente, Laura Rodríguez advierte en él la oculta mano de la diplomacia frncesa ${ }^{14}$.

Sea como fuere, lo que aqui nos interesan son las consecuencias, que se hicieron sentir con suma rapidez. La represión inmediata fue dura y despiadada, cuando ya el pueblo saltaba de alborozo, creyendo haber alcanzado sus objetivos. A los pocos días, para que sirviese de advertencia y escarmiento, fue torturado y descuartizado en la Plaza Mayor el murciano Juan de Salazar, acusado de haber jurado en público que «había de terminar con los Borbones». Fue la única voz discordante entre los devotos vivas a la Monarquía, y hubo de pagar con su vida tan osado y extemporáneo comentario. Todavía faltaban más de veinte años para la Revolución francesa.

Las medidas políticas de mayor trascendencia fueron adoptadas al año siguiente, con lo que 1767 se convierte en año crucial de la historia de España. Para comenzar, tienen lugar cambios sustanciales en las altas esferas de la gobernación del país. Con el nombramiento del conde de Aranda para presidir el Consejo de Castilla, se rompe la tradición de ser ocupado este segundo puesto de la Monarquía por un miembro de la jerarquía eclesiástica. Con ello se pone en práctica la doctrina regalista, que, sin pretender todavía la separación Iglesia-Estado, intenta eliminar a ésta de los asuntos civiles.

En el mes de abril se toma la medida más espectacular: la expulsión de los jesuitas de todos los dominios del Rey de España, en virtud del dictamen secreto del fiscal Campomanes, recientemente publicado ${ }^{15}$. Las demás órdenes religiosas han de someterse a las reformas propuestas por el Rey, al

14 Los últimos en ocuparse del tema han sido Pierre Vilar, «El motín de Esquilache y las crisis del Antiguo Régimen» y Laura Rodríguez, "EI motín de Madrid de 1766», ambos en Revista de Occidente, núms. 107 y 121, de 1972 y 1973, respectivamente.

15 Por la Fundación Universitaria Española, en 1977. 
mismo tiempo que se ven desplazadas de las Universidades, a las que también alcanzan las medidas de secularización. Se legisla restrictivamente sobre las publicaciones de libros y folletos, con la orden de que en adelante no fuesen permitidas las imprentas conventuales; se recrudece la censura y se prohiben absolutamente los romances y pronósticos ${ }^{16}$.

La gobernación del Estado recae definitivamente en ministros nacionales, partidarios de las reformas, manteistas en su casi totalidad. Los nobles, en cuanto tales, pierden sus prerrogativas tradicionales al frente de los negocios públicos. Ya no será la cuna sino el propio mérito el único motivo para acceder a tales cargos. Se prepara en secreto la transformación de los Colegios Mayores, reducto de la nobleza y semillero exclusivo hasta entonces de cuantos cargos dependían de los Consejos. A partir de ese momento, el dominio del Rey es absoluto, avalado por la fidelidad de sus más allegados colaboradores.

Por lo que respecta al pueblo llano, protagonista visible de los disturbios, las medidas que se toman son también de la mayor importancia. Para comenzar, se perfila una política de supresión de la mendicidad y exaltación del trabajo, que tiene su complemento en la revitalización de los hospicios, donde se obliga a trabajar a vagabundos y desocupados ${ }^{17}$. EI activo Olavide, hasta entonces director del Hospital de San Fernando, es encargado de organizar las Nuevas Poblaciones de Sierra Morena, en un intento de aumentar el atractivo de las labores agrícolas, con el reparto de tierras, y contener así las periódicas migraciones de pobres campesinos hacia la capital del Reino.

En cuanto a ésta, los acuerdos adoptados fueron de muy diversa índole y alcance. En principio, el conde de Aranda quiso hacer olvidar el motín fomentando las fiestas, entre ellas los bailes de máscaras, y abriendo al público un nuevo paseo en el Retiro, con más de dos mil sillas y estableci-

16 Véanse mis libros: Romancero popular del siglo XVIII y La prensa española en el siglo XVIII: diarios, revistas y pronósticos, publicados por el Consejo Superior de Investigaciones Científicas en la colección “Cuadernos bibliográficos», núms. 27 (1972) y 35 (1978).

17 A fines de año se reimprime en Madrid la obra de fray Juan de Medina, benedictino del siglo XVI, La charidad discreta, practicada con los mendigos, y utilidades que logra la República en su recogimiento. El editor es Luis del Valle Salazar, consejero de Castilla. (Hay ejemplar en la Biblioteca Nacional, V. E. Caja 383/52). 
mientos de café y bebidas refrescantes. En cuanto al rústico Paseo del Prado, escribe el 15 de junio el marqués de San Leonardo: “El Prado se va a componer y quedará hermosísimo, pues será un bulevart para coches y gentes de a pie cual no lo habrá mejor en Europa, en medio la estatua ecuestre del Rey ${ }^{18}$.

Pero la previsión de los gobernantes no se detiene aquí, sino que va más allá, profundizando en la problemática municipal, con dos decretos que pretenden la reforma de la administración local. Por el primero se crean los cargos de diputados y síndicos personeros del Común en el seno de los Ayuntamientos, elegidos por el pueblo en votación secreta, con la obligación específica de velar por la política de abastos, con atribuciones semejantes a los demás cargos concejiles. Este hecho, con precedentes en la España del siglo XVI, «nos sitúa ante una medida extraordinariamente avanzada», como escribe el profesor Rodriguez Casado ${ }^{19}$.

El segundo de los mencionados decretos hace referencia a los alcaldes de barrio, y de ellos voy a tratar más específicamente. A propuesta del conde de Aranda, aprueba S. M. la real cédula del 6 de octubre de 1768, por la que "se divide la población de Madrid en ocho Cuarteles, señalando un Alcalde de Casa y Corte y ocho Alcaldes de Barrio para cada uno" ${ }^{20}$. Su fin no es otro que controlar con mano dura el orden público, tan seriamente amenazado con el motín. La capital de España queda dividida administrativamente en ocho distritos o cuarteles, a cargo cada uno de un Alcalde de Casa y Corte, que ha de ser (responsable de su tranquilidad y de perseguir los delitos que se cometan en él, con amplia jurisdicción criminal, como Ia tiene cualquier alcalde ordinario en su pueblos. Estaba obligado a residir en la demarcación de su cuartel y se le asignaba un despacho en

18 Véase el art. cit. de José Cepeda Adán.

19 V. Rodríguez Casado, La administración pública en el reinado de Carlos III. Oviedo, Cuadernos de la Cátedra Feijoo, núm. 12 (1961). Estos párrafos fueron transcritos literalmente en su libro La política y los políticos en el reinado de Carlos III. Madrid, Rialp, 1962, pp. 156-161.

20 REAL CEDULA de Su Magestad a consulta de los Señores del Consejo: Por la qual se divide la población de Madrid en ocho Quarteles, señalando un Alcalde de Casa y Corte y ocho Alcaldes de Barrio para cada uno: se establecen dos Salas Criminales, con derogación de fueros en lo criminal, a de policía, y otras providencias para el mejor $y$ más explicito gobierno de Madrid. Madrid, Antonio Sanz, 1768. 8 hs. 29 cm. (Hay ejemplar en el Archivo de Villa, 2-191-1). 
la Cárcel de Corte. Estaría asistido por dos porteros, cuatro alguaciles y ocho Alcaldes de Barrio, encargado cada uno de ellos de los ocho barrios en que, a su vez, se dividía cada cuartel.

Este Alcalde debería ser «vecino honrado» del propio barrio, elegido por los vecinos, (en la misma conformidad» que los diputados y personeros del Común. Sus atribuciones, que eran amplísimas, como veremos, quedan establecidas así en la real cédula: «matricularán todos los vecinos, y los entrantes y salientes; celando Ia policía, el alumbrado, la limpieza de las calles y de las fuentes; atenderán la quietud y orden público, y tendrán jurisdicción pedánea para hacer sumarias en casos prontos, dando cuenta incontinenti al Alcalde del Cuartel; se encargarán de la recolección de pobres para dirigirlos al Hospicio, y de los niños abandonados, para que se pongan a aprender oficio o a servir». Prosigue el texto legal aclarando que «a fin de que sean conocidos y nadie pueda dudar de sus facultades y jurisdicción, podrán usar de la insignia de un bastón de vara y media de alto, con un puño de marfil». Y finaliza añadiendo que «estos empleos se deben reputar como actos positivos y honoríficos de la República, y que se juren como tales en el Ayuntamiento de Madrid, asentándolos en los libros capitulares, sirviendo en adelante a sus familias para pruebas y otros casos de honor».

Dos semanas después se publica una Instrucción ${ }^{21}$, en la que se especifica un poco más: la elección se haría en diciembre de cada año, «por los vecinos del respectivo, ante el Alcalde de Casa y Corte de su Cuartel», debiendo jurar el cargo en el Ayuntamiento el primer día del año siguiente. Se les entregaría una lista con las calles y manzanas de su jurisdicción y comenzarían por matricular a todos los vecinos, «con el nombre, empleo, estado, hijos y sirvientes». Llevarían al día un asiento de posadas y mesones, con el exacto movimiento de huéspedes, tanto de posadas públicas como secretas. El control sería más riguroso en figones, tabernas y botillerías, las cuales "visitarán a diferentes horas y repetidamente». También estaría a su cargo el cuidado de fuentes y empedrados, la exactitud de precios,

21 INSTRUCCION que deben observar los Alcaldes de Barrio, que para el más expedito y mejor gobierno se han de nombrar, o elegir en cada uno de los ocho Quarteles en que se divide la población de Madrid, en cumplimiento de lo mandado en la Real Cédula de seis de este mes, expedida a consulta del Consejo de diez y nueve de Setiembre de mil setecientos sesenta y ocho, y lo que han de egecutar los jueces Ordinarios en las causas de Familia. [s.l.s.i.s.a.] [1768] 8 fols. $29 \mathrm{~cm}$. (Hay ejemplar en el Archivo de Villa, 2.191-1). 
pesos y medidas en las tiendas de comestibles, la lucha contra la mendicidad y la vagancia, la puntualidad en el trabajo y la salud pública. Como se ve, un buen programa de actuación pública cuyo cumplimiento exigía notables dotes de energía y dedicación al servicio del pueblo.

El 24 de noviembre el conde de Aranda entrega al Corregidor de Madrid (entonces D. Alonso Pérez Delgado) los bastones de mando para los sesenta y cuatro Alcaldes de Barrio que resultasen elegidos al mes siguiente. La fórmula del juramento incluía la «defensa del misterio de la Purísima Concepción", como era entonces corriente en todos los empleos públicos, además de «ejercer bien y legalmente, como Dios manda, con celo del servicio de S. M. y el bien común, el oficio de Alcalde de Barrio». En el Archivo de Villa se conserva un impreso con el resultado de las primeras elecciones ${ }^{22}$ y la certificación de todas las demás, hasta el año de 1802, en que se amplían a diez los ocho cuarteles anteriores ${ }^{2}$.

"Todo esto se realiza - comenta Rodríguez Casado- poco después de un motín, y a consecuencia del mismo, al propio tiempo que se estudian sus causas. Si los magistrados del Consejo de Castilla no hubiesen descubierto que el pueblo fue simple instrumento en manos de personas más principales, no se hubieran atrevido a una modificación tan importante que entregaba gran parte de la vida local en manos de ese mismo pueblo y la arrancaba de las clases altas de la sociedad" ${ }^{24}$

La institución de los Alcaldes de Barrio resultó un acierto. No así la

22 ELECCION que se ha hecho de Alcaldes de Barrio, por los vecinos que de cada uno han concurrido a la convocatoria. Madrid, Viuda de Manuel Fernández, 1768. 16 pp. $14 \mathrm{~cm}$. Aprovechando la circunstancia, Juan Francisco González publica Madrid dividido en ocho Quarteles, con otros tantos Barrios cada uno: Explicación de ellos, sus recintos, nombres que les han dado, calles y plazuelas que comprehneden y señores Alcaldes de la Casa y Corte de S.M. a quien se han encargado, según la nueva planta que se ha establecido. Madrid, Gabriel Ramírez, 1768. 72 pp. 14 cm. (Hay ejemplar de ambos impresos en el Archivo de Villa, 2-191-1).

23 REAL CEDULA de S.M. y Señores del Consejo, por la qual se divide la población de Madrid en diez Quarteles, en lugar de los ocho en que actualmente está repartida, baxo los títulos y con la asignación de Barrios que se expresan. Madrid. Imp. Real, 1802. 3 hs. $30 \mathrm{~cm}$. (Hay ejemplar en el Archivo de Villa, 2-191-3). El expediente para la publicación de esta Cédula se conserva en el AHN, Consejos, 2198 (12).

24 Rodríguez Casado, La Política... pág. 161. 
coordinación de todos ellos con Ios ocho Alcaldes de Cuartel y con el Corregidor. Este es asunto virgen aún en la investigación histórica de la Villa y Corte, que debería ser abordado con urgencia. Lo cierto es que la experiencia aconsejó a Carlos III la creación de un nuevo cargo, el de Superintendente General de Policía, "para Madrid, su jurisdicción y rastro», con obligación de velar por las leyes, autos acordados, bandos, decretos y demás providencias del Consejo, con dependencia de la primera Secretaría de Estado. Era, por tanto, independiente del Ayuntamiento, y a él quedaban subordinados, tanto el Corregidor como los alcaldes. EI preámbulo de la real cédula, publicada con fecha 17 de marzo de 1782, justifica tal decisión "por el aumento y extensión que ha tenido de algunos años a esta parte la población de Madrid», lo cual exige que, (a semejanza de lo que se practica en todas las demás Cortes, haya en esta mía una persona de autoridad, celo, experiencia y rectitud que, sin distraerse a otros objetos, cuide particularmente y sea responsable de aquellas reglas y providencias [de Policía], sin perjudicar ni disminuir las facultades y obligaciones que hayan ejercido hasta ahora y tengan otras Personas y Tribunales). Dos días después era nombrado para el cargo Don Bernardo Cantero de la Cueva ${ }^{25}$.

Fácilmente se comprende que su puntual ejercicio no resultara cosa fácil, por el cruce de tantas competencias. Y así, ocho años más tarde aún continuaban los pleitos ${ }^{26}$ hasta que, con la crisis ministerial de febrero de $1792^{27}$, ocupa de nuevo el poder el conde de Aranda, quien suprime la Superintendencia porque «su autoridad interrumpía el ardor de las otras». Al parecer, Godoy no hace innovación alguna en este aspecto, pero en julio de 1804, con Ceballos en la Secretaría de Estado, se crea un Juez de Policía para Madrid, “con inhibición de todo otro Juez y Tribunal». Fracasa la fórmula, y el 13 de diciembre de 1807 se restablece la Superintendencia General de Policía de Madrid, que habría de hacer frente a los grandes acontecimientos políticos del mes de mayo siguiente ${ }^{28}$.

25 REAL CEDULA de S.M. y Señores del Consejo, por la qual se manda guardar y cumplir el Real Decreto aquí inserto, por el qual se crea una Superintendencia General de Policia para Madrid, su jurisdicción y Rastro, con plaza efectiva en el Consejo, $y$ asistencia a él y su. Sala de Gobierno, con lo demás que se expresa. Madrid, Pedro Marín, 1782. 6 hs. $30 \mathrm{~cm}$. (Hay ejemplar en el Archivo de Villa, 1-30-35).

26 AHN, Conseios, leg. 1285 (1).

27 Véase: J. A Escudero, Los cambios ministeriales a fines del Antiguo Régimen. Universidad de Sevilla, 1975.

28 Archivo de Villa, 1-30-35. 
Esta es, a grandes rasgos, la historia legal de la justicia y policía madrileñas durante el siglo XVIII, pero no me hubiera decidido a tratar este tema, excesivamente teórico por la frialdad de los textos legales, a no ser por el fortuito hallazgo de un excepcional documento. Se trata del diario manuscrito de un Alcalde de Barrio, que lo fue durante los años 1791 y 1792 en el barrio de la Comadre, corazón del castizo Lavapiés. Se conserva en la sección de Estado del Archivo Histórico Nacional, perdido en un legajo de «varios», en el que nadie podía sospechar de su existencia ${ }^{29}$. Su autor, Pedro García Fuertes, había sido secretario primero de la Diputación y Junta de Caridad del barrio desde marzo de 1788 hasta junio de 1790. A fines de este año fue elegido, en votación secreta, por sus convecinos para desempeñar la alcaldía del barrio, lo que hizo con eficiencia y entrega dignas de todo elogio, como veremos. No he hallado, desgraciadamente, la matrícula de vecinos, ni ningún otro diario similar, pero es muy posible que se hallen en otros legajos de la misma sección, los cuales constituirian una excelente base documental para un estudio sociológico del Madrid dieciochesco.

Según Mesonero Romanos, «aquellos sitios costaneros y despejados por donde ahora corren las calles de Jesús y María, de Lavapiés, del Olivar, del Ave María, y sus travesías, eran ya célebres [en el siglo XVI] por sus afamados ventorrillos, tabernas y bodegones... $\sin$ que en ninguna de ellas exista edificio, monumento ni recuerdo histórico de importancia» ${ }^{30}$. Posteriormente, el lugar se fue transformando hasta convertirse en "corazón de los barrios bajos madrileños, estampa de sainete, recuerdo desgarrado de manolas de rumbon ${ }^{31}$ cuya vida y costumbres fueron descritas con maestría literaria por Don Ramón de la Cruz en sainetes como El careo de los majos, Los pobres con mujer rica, El deseo de seguidillas y sobre todo en la tragedia burlesca Manolo (1769).

En la división de Madrid del año 1768 el cuartel $G$ se titulaba sim-

29 Libro de asientos y toma de razón de las cosas y casos que me ocurran el presente año de 1791 como Alcalde de Barrio de este de la Comadre $70 \mathrm{hs.} 30 \mathrm{~cm}$. Hay otra manuscrito del año siguiente, que se intitula: Libro de fechos, o asiento de los recursos, süplicas y pretensiones que ante mí han pasado y me han echo en todo el presente año los vecinos. de este barrio de la Comadre, coma Alcalda que soy dé él. $50 \mathrm{hs} .30 \mathrm{~cm}$. Se conservan en el AHN, sección de Estado, leg. $3011\left(1 .^{\circ}\right)$.

30 A. Mesonero Romanos, El antiguo Madrid, Cap. XIV: «Lavapiés».

31 José del Corral y José M." Sanz, Madrid es así. Una semana de paseante en Corte. Madrid, 1953, p. 113. 
plemente "Lavapiés», y estaba integrado por los barrios del Hospital General, Santa Isabel, Ave María, Trinidad, San Isidro, San Cayetano, la Paz y la Comadre. Este último, objeto de nuestro estudio, comprendía catorce manzanas, situadas entre el convento de la Merced y las calles de Lavapiés, Mesón de Paredes y Sombrerete, dentro de cuyos límites se incluían las calles de la España, San Pedro Mártir, Juanelo, Pingarrona, Cabeza, Esgrima, Calvario, Jesús y María, Esperancilla, Cruz de Caravaca y de la Comadre, más propiamente Comadre de Granada, como especifica el plano de Espinosa (1769). También pertenecía a la jurisdicción de nuestro alcalde la Fuente de Relatores, al extremo del convento de la Merced, en lo que más tarde, tras el derribo del convento, sería la Plaza del Progreso y después de Tirso de Molina.

El barrio, como es notorio aún en nuestro tiempo, carecía de edificios nobles, a excepción de la casa-palacio del conde de las Torres, hoy solar, en la calle Mesón de Paredes. El resto de las fincas urbanas eran de carácter modesto, a tenor del vecindayio, con una superficie variable, entre mil y tres mil pies cuarlrados, como se puede comprobar en la Planimetría de 1768. En contraste, el solar del conde de las Torres tenía 38.989 pies cuadrados de superficie, mayor él solo que once de las manzanas del barrio, donde se alojaban 144 vecinos. En el conjunto de las catorce manzanas habia 217 casas, en las que habitaban 278 familias. Ninguna iglesia estaba ubicada dentro de los límites del barrio, aunque en sus alrededores se encontraban San Lorenzo, San Cayetano, las Escuelas Pias y el convento de la Merced, donde antaño viviera Tirso de Molina, y que resulta ser, según la Planimetría, el principal propietario de las humildes viviendas del barrio, seguido del Colegio Imperial y otros varios conventos y cofradías. Las calles confluían en la irregular plazuela de Lavapiés, verdadero centro social del barrio, con su fuente de piedra, sustituida años después por otra de hierro.

Las casas eran de dos plantas por lo regular, aunque las había también de cuatro o cinco pisos, como se puede observar en la maqueta de Gil de Palacio, casi todas con buhardillas en lo alto y tiendas o talleres en el piso bajo, con un patio central, alguno de los cuales aún subsiste, de escasas dimensiones y forma alargada. En la calle de la Comadre había, al menos, tres sastres, dos zapateros, un barbero, una buñolería y una fábrica de tintas de la imprenta de Sancha; en la de la Esgrima, una buñolería y una tahona, además de un cirujano; en la calle ancha de Lavapiés, una librería, una carpintería, una tienda de chocolate, un molino de papel y la taberna llamada “El Jardinillo»; en la de Juanelo, un sacamuelas; en Cruz de Caravaca, taberna y sastre; en Mesón de Paredes, una taberna (frente a la calle 
del Oso) y varios menestrales: peluquero, sastre, vidriero, relojero, colchonero y zapatero. La plazuela de la Fuente de Relatores contaba con dos bodegones y una taberna. Varias veces se citan en el diario el "Corralón de Jesús y María» y el "Corralón de las Escobas», casas de vecinos de dos plantas, con patio y servicios comunes, de mayores dimensiones que las restanles, y que constituyen el precedente de las casas de vecinos construidas un siglo después, con cuatro o cinco plantas y mayor capacidad, como en el caso de la "Corrala», que aún se mantiene parcialmente en pie, en la vecina calle de Tribulete.

Estos pobres menestrales y jornaleros, con sus respectivas mujeres, hembras de armas tomar, serán los asiduos protagonistas del diario de nuestro alcalde. A los oficios masculinos ya citados hay que añadir en el barrio los de albañil, latonero, mozo de alumbrado, pocero, lacayo, tejedor, estanquero y otros mozos sin más oficio que la navaja y el desplante, como "el Calelo» y (el Piche», que aparecen en las páginas del diario como matones sin escrúpulos. Todos ellos fueron inmortalizados por Goya en más inocentes entretenimientos, como el baile campestre o el juego de la cometa. Las mujercs suelen ser lavanderas, buñoleras, panaderas, aguadoras, revendedoras, posaderas y, en todo caso, majas de rumbo y tronío, más de tronío que de rumbo, a juzgar por los alborotos que producían. También fueron idealizadas por Goya, como lavanderas, floristas y mozas de cántaro. Aunque estos cuadros, rebosantes de luz y alegría, no reflejen el drama de la vida cotidiana, nos introducen, al menos, en las costumbres y vestidos de los majos en el Madrid de Carlos IV, con tal de que scpamos adivinar en ese mundo social el trasfondo de miseria moral y material que el pincel del artista ha querido dejar fuera del lienzo.

Lo cual no es óbice para que en el barrio viviesen gentes honradas, o al menos que aparentasen serlo, con sus ínfulas nobiliarias, de que hacían ostentación colocando sus blasones en los portales de sus casas, para asombro del ingenuo visitante que creyese incompatible la pobreza con la hidalguía. Por supuesto, encontramos en el barrio profesionales de mayor relieve social, como militares, relatores, artistas y pequeños empresarios, como la imprenta de Melchor Cano, de la que salieron importantes publicaciones del XVIII, situada en la calle de Jesús y María. En la de Lavapiés había fallecido en 1743 el arquitecto madrileño Manuel de Moradillo ${ }^{32}$.

32 Virginia Tovar Martín, “Una familia madrileña de arquitec' s. los Moradillo», en Ville de Madrid, núm. 57, 1977, pp. 23-26. 


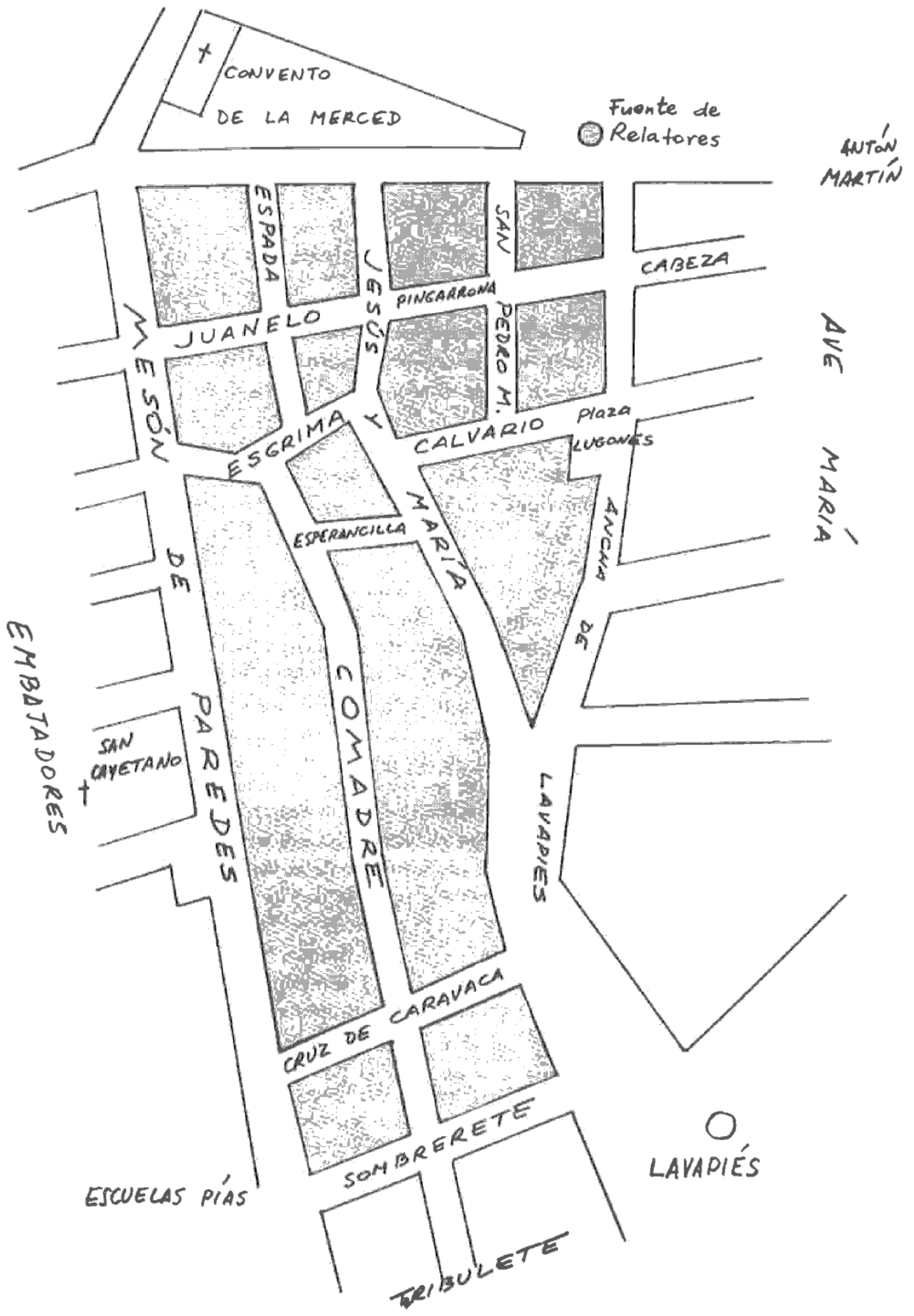


Veamos con cierto detalle la actuación del alcalde en el año de 1791. Comencemos por decir que era persona generosa, como lo atestiguan múltiples datos del diario, en el que anota minuciosamente todos los gastos del cargo, que en el año suman 1.184 reales. Un gasto fijo eran los seis reales que le cuesta la invitación diaria a vino y bizcochos a sus acompañantes de ronda. En una ocasión da diez reales de limosna a Santiago Hernández de la Vega, pobre de solemnidad, cuyo padre, ya difunto, había sido alcalde de este barrio, pero que «la Diputación de Caridad no le había querido socorrer por no ser de aquí». Y en otra página, escribe: "Habiendo pasado S. M. por mi casa, salí incontinenti a acompañarle, y siendo como era [el enfermo] un menestral de la calle Ancha de Lavapiés, y viendo tanta miseria, le di diez reales para que pusiesen un pucheron. El día primero de año, a poco de tomar posesión de su cargo, se le avisó de que un pobre estaba tendido en la calle con dolor de ciática. Ayudado por dos mozos, le llevó a su casa, le hizo reconocer por un médico y le proporcionó un caldo "con el que provisionalmente se le socorrió». Con un presupuesto de seiscientos reales mensuales que le adjudicaba la Junta de Caridad, debía atender a la miseria más absoluta, con casos de increíble necesidad. Una vez entrega cuatro reales para «un puchero» a un parado, casi ciego, cuya mujer habia dado a luz. Otra, firma un certificado de pobre a un oficial de sastre, que lo necesitaba para conseguir una limosna prometida por el duque de Granada.

En un informe al Alcalde de su Cuartel, escribe el diarista: “En el barrio de la Comadre hay infinidad de vecinos, especialmente tejedores y pasamaneros, que por faltar las primeras materias, tienen abandonados sus talleres, y por tanto, indigentes y necesitados, como sus mujeres e hijos... y hay crecido número de niños y niñas que no asisten a la escuela por no tener para pagar a los maestros. A tal extremo de pobreza llegaban algunas familias que el alcalde se ve en la precisión de ingresar en el Hospicio a varias niñas, a petición de la propia madre, por carecer de medios con que mantenerlas. Otras son enviadas al Hospital, afectadas por la tiña, a fin de evitar el contagio.

En este ambiente de miseria corporal y espiritual ha de desarrollar su cometido el alcalde don Pedro García Fuertes. Y lo hace con energía y prudencia, anotando sabrosos comentarios sobre la vida de los barrios bajos madrileños, idealizados por el sainetero Ramón de la Cruz. A todo atiende su 
solícita preocupación: ordena quitar las piedras, basuras y estorbos de las calles ${ }^{33}$, previene los incendios, apacigua los ánimos, hace cumplir los bandos y ordenanzas, protege al desvalido, ayuda al necesitado, amonesta al ocioso, obliga a cumplir la palabra dada y multa a los infractores, encarcela al criminal y vigila en todo momento la convivencia de los vecinos a fin de mantener el orden público y la moderación de las costumbres.

Como vemos, sus atribuciones eran amplísimas, y su actividad incansable, aunque los frutos fuesen escasos, a la vista de las reincidencias. A él acuden cuantos pretenden la resolución de un agravio o la exposición de una simple queja. Si un perro muerde a los transeúntes, obliga al dueño a ponerle bozal, y cuando la queja se repite ordena la muerte del animal. Si en la imprenta de Cano arrojan a la calle las aguas tintas, manda arreglar el sumidero a costa del impresor. Cuando recibe una denuncia de descuido en el fuego encendido en una buhardilla, ordena el desalojo inmediato de ésta.

Las quejas se suceden sobre los ruidos que impiden dormir la siesta: lo mismo si es un maestro zapatero o los pavos de una vecina. En ambos casos se trata de un patio interior y hace que tanto los animales como el zapatero permanezcan dentro de su vivienda. También dentro de ella se debía guardar la basura durante toda la semana, sin sacarla a la calle hasta el miércoles, que era el día de recogida. Y si los malos olores son producidos por un pozo negro repleto de inmundicia, avisa de inmediato al Corregidor para que ordene vaciarlo.

Alertado por un vecino de que en la calle Cruz de Caravaca, a las doce de la noche, alguien había volcado por la ventana una «jofaina de orines», acude a casa del infractor, que resulta ser un capitán retirado, el cual se excusa diciendo que (la Y griega está en el cuarto bajo» y que ningún cuarto de la casa tiene «tarjea para conducir las aguas». Al día siguiente ordena al administrador de la casa que haga las obras pertinentes para cumplir la nueva legislación sobre la limpieza de Madrid. Ya no eran los tiempos -bastante cercanos, por cierto — del ;agua va! que tan mala fama había

33 Precisamente, en el mes de noviembre, el Corregidor Armona escribe al delegado municipal de limpieza, Juan García de Lama: “He advertido varias veces, con sumo disgusto mío, que se padece mucho descuido, asi en la observancia de lo que está prevenido por los bandos públicos de Policía, como en cuidar de que las calles estén francas y desembarazadas de materiales de las obras y otros estorbos, para el más cómodo tránsito de las gentes de a pie y de coches». Los encargados de tal menester eran los celadores, que se habían quedado reducidos a cinco - aunque en un principio fueron trece- por la impuntualidad con que el Ayuntamiento les abonaba el sueldo, que era de 300 ducados al año. (Archivo de Villa, 1-30-36). 
dado a la eapital de España. Con la misma preocupación por la limpieza callejera, al llegar el verano propone a las mujeres pobres del barrio que se ofrezcan a los vecinos pudientes para barrer y regar las puertas de sus casas, aunque antes debían matricularse en el (cregistro de barrenderas». Con la misma solicitud por el cumplimiento de la ley impide las tertulias nocturnas en los portales de las viviendas en las calurosos noches de verano.

También los humos producian molestias al vecindario ${ }^{34}$. Recordemos que en Lavapiés había por entonces ocho tahonas, cuatro buñolerías y cinco fábricas de yeso, amén de las invernales castañeras, que hacían irrespirable en ocasiones el aire del barrio. De los numerosos testimonios encontrados quiero transcribir aquí sólo la denuncia que el 10 de junio hace nuestro alcalde el Corregidor, sobre "lo indecente y sucio ( $y$ expuesto a un incendio) del bodegón que está frente a la Merced calzada, esquina a la calle de San Pedro Mártir, que tiene a su cargo María Francisca Fernández. Se me han dado algunas quejas, tanto por el dueño de la casa como por los inmediatos inquilinos... de que a deshoras de la noche, pone a cocer las ollas de callos que guisa, y para ello quema huesos, pezuñas y otras porquerías que apestan la vecindad, por no tener más salida el humo que la de una ventanilla que cae a la expresada calle».

Los niños son tema de especial atención para el alcalde. Apenas iniciado su mandato, el 3 de enero, un buñolero se lamenta de que su hijo de once años no ha vuelto a casa en todo el día, al parecer por haberse marchado a Chamartín con una vecina, vendedora de carne. El alcalde va a casa de dicha mujer y espera pacientemente su regreso, para amonestarla. Una semana después, la viuda de un abogado va a verle para exponerle los problemas que tiene con su hijo, tonsurado de prima y estudiante en Santo Tomás, que «se hallaba mal entretenido, no asistía con puntualidad a los estudios, ni a su casa, quedándose fuera de ella algunas noches, y que varias veces le había hurtado algunos reales». El alcalde averiguó su paradero, enterándose de que sus ausencias eran debidas al juego del «chito» en la buñolería de su calle. Multó al buñolero con seis ducados y le dio orden de que no le adnitiese más, por ser contra el deseo de los padres, amenazando al chico con "ponerle en un cepo por ocho días a pan y agua». Este mismo castigo lo hizo efectivo algún tiempo después con algunos muchachos

34 En 1792 había en Madrid 18 fábricas de yeso. Por R. O. de 7 de mayo de 1803 se ordenó trasladar estas industrias a las afueras. Véase: J. A. Martínez Bara “Problemas de policía urbana madrileña en el ipasadom, en Anales del Instituto de Estudios Madrileños, VI, 1970, pp. 375-384. 
que encontró jugando a los naipes en un portal de la plazuela de Lugones. En otra ocasión encerró en el cuartel de Santa Isabel al hijo de un vidriero por haber robado a su padre un almirez; y lo mismo hace con Isidro del Campo, a ruegos de su madre, que lo acusa de desobediencia y malas costumbres. A otro que fue acusado de malos tratos a su madre, le obligó a pedirle perdón de rodillas y a besarle la mano.

A la maestra de niñas de la escuela gratuita de la Diputación de Caridad del barrio le habla severamente para que las niñas no causaran alboroto a la salida de escuela, «sin ponerse a hacer sus necesidades en la calle, pues lo hacían deshonestamente, a más de emporcar las aceras y criarse sin temor y respeton. Otro día la pone en evidencia por dar preferencia a las niñas de pago, en menoscabo de la atención y cuidado que debía a las pobres de la Diputación. Persigue sin cesar a los muchachos que forman pandillas, escapando a la obligación escolar, para alborotar en la calle o jugar a los naipes, su ocupación preferida. Lo malo es que, cuando llega el celoso alcalde, ya los pájaros han volado, y en el improvisado "garito» sólo encuentra las manoseadas barajas.

Las denuncias son frecuentes contra las lavanderas, que bajaban cada día con la ropa a cuestas hasta los lavaderos a orillas del Manzanares. Hay quien las acusa no sólo de lavar mal las prendas, sino incluso de devolverlas llenas de piojos.

En la calle de la Comadre, núm. 19, en un cuarto del corredor, vive una pobre mujer, casada con un botonero, que por ochenta reales al mes amamanta a un recién nacido. La reprimenda no se hace esperar cuando el alcalde se entera de que, contra lo estipulado, se ha atrevido a tomar otro niño para criar, confiada, sin duda, en su bien provista despensa.

Tampoco faltan en el diario ejemplos de hurtos a los que ha de hacer frente el alcalde, aunque su misma cuantía y entidad da fe de la absoluta indigencia de los desgraciados ladrones. Los casos más llamativos son los de los poceros, que, durante la noche, al tiempo de hacer su desagradable trabajo, hurtaban de ventanas y balcones la ropa tendida, además de «chorizos, velas y cortinas». $\mathrm{O}$ los traperos que, a «título o pretexto de buscar el papel y los trapos, "no han dejado ya en Madrid basurero alguno con llave, picaporte, cerrojo ni cerradura, habiéndolas robado todas».

Un buen día, los padres escolapios van a quejarse de que los vecinos de la Comadre asisten a misa en su recién estrenada iglesia «en pernetas, remangados los brazos, con las chupas al hombro y herramientas de su 
ejercicio». Y allá se va el buenazo de don Pedro, a las siete de la mañana de cada día festivo para evitar esta falta de respeto. El día 20 de agosto, en que se celebraba en la iglesia el jubileo de las cuarenta horas, estuvo a la puerta desde las seis de la mañana hasta la una, y desde las cuatro de la tarde hasta el anochecer. Lástima que tanto sacrificio resultase inútil a la postre, como él mismo confiesa, pues el día de San Miguel vuelven a aparecer los feligreses con la misma falta de compostura, «sin haber servido nada - escribe con desaliento - nuestras tareas, prevenciones, amonestaciones, castigos y demás, por lo relajado del barrio, necesitando éste de otras mejores diligencias»).

Contra lo que se podía pensar, el alcalde interviene incluso en el pago de las deudas contraidas por los vecinos. Todo con tal de que no se altere el orden público. Un día de febrero obliga a pagar a la Hermandad del Amparo una deuda de 56 reales que debía a un pobre albañil. Sebastián de los Santos, panadero, se queja de que Francisco de Mora le debe 77 reales de pan, y cuando comprueba que éste no tiene tal cantidad, conviene con el demandante en un pago aplazado de diez reales mensuales. En otra ocasión el plazo es de una peseta semanal. Los mayores pleitos económicos tienen su causa en la compleja trama de arriendos y subarriendos, tan comunes en aquellos años. Si comprueba la veracidad de la denuncia no duda en expulsar al inquilino deudor y poner candado en el cuarto.

A raíz de los acontecimientos revolucionarios de Francia, el Gobierno ordena a los Alcaldes de Barrio el padrón de todos los extranjeros de su demarcación. Gracias a ello sabemos que en el barrio de la Comadre vivian doce franceses, diez italianos y un flamenco, "todos católicos», el más antiguo de los cuales era el italiano Miguel Allori, "vaciador de estatuas», que llevaba 25 años viviendo en el núm. 36 de la calle de la Comadre. En la misma calle vivían Domingo Micheli y sus tres hijos, escultores, y un francés, criado desde hacía cuatro años del médico Masdeval. En Mesón de Paredes residían algunos franceses: los hermanos Pedro y Gregorio Burguien, pintores, un peluquero y un panadero. En la calle Ancha de Lavapiés, otro francés, casado. fabricante de papel, desde hacía veinte años, y otro, fabricante de sombreros. En Jesús y María otro sombrerero, italiano.

Aparte el problema específico de los extranjeros, el alcalde tenía orden severa de perseguir la inmigración interior. En febrero desaloja y manda volver al pueblo a varias familias que habían venido a la Corte «sin licencia alguna ni motivo», malviviendo en pobres buhardillas subarrendadas. En abril devuelve al pueblo de Dos Barrios a un pobre de aquella localidad que estaba pidiendo limosna por la Comadre. Poco des- 
pués, a dos mujeres sin casa, oficio ni familia, inmigrantes, les da un pedazo de pan y otro de queso y cuatro reales para salir de Madrid. Todo inútil. En este terreno, más difícil era hacerse obedecer que luchar contra el viento. Madrid era - y obviamente, sigue siendo - un polo de atracción irresistible.

El cometido del alcalde se extendía, como sabemos, al correcto abastecimiento de la población. Por ello, visita las tiendas, comprueba los pesos y medidas, averigua si las vasijas de aceite, manteca y vinagre están limpias, y los comestibles «sin gusanos, polillas ni otros insectos», los manteles de las bodegas limpios, los precios ajustados al arancel. El 4 de noviembre alguien se queja de que en la buñolería de la calle de la Comadre pesaban mal los buñuelos y los daban crudos. Acude presuroso a la freiduría y el dueño aduce en su defensa que "la prisa de los concurrentes hacía que los buñuelos salieran sin freirs; y en cuanto al peso, que los que iban a buscarlos se los comían por el camino. Cuando hay altercado en la fuente, establece que «tienen privilegio los vecinos, de quienes eran las aguas».

La vigilancia de posadas, mesones y tabernas es otro de los más arduos cometidos del alcalde. El nuestro visita el 24 de julio todas las posadas del barrio, "a fin de averiguar si los huéspedes estaban bien asistidos, si se recogían a horas cómodas, sin causar nota ni escándalo. Si tenían visitas de mujeres sospechosas, si eran impertinentes, díscolos y de mal genio, si los negocios que los habían traído a la Corte estaban en estado de conclusión». Este vigilante control se complementa con el ejercicio sobre las tabernas, en especial sobre la obligación de cerrar a las diez de la noche y la prohibición de los juegos de azar ${ }^{35}$. A los seis días de ocupar la alcaldía, «convoqué a mi casa - escribe D. Pedro- a todos los taberneros del barrio y les enteré de todas las órdenes y providencias dadas para que no permitiesen en sus casas juegos, mujeres ni meriendas, cerrando sus puertas a las horas prevenidas, echando fuera toda la gente». Tan frecuentes como los juegos de naipes eran las fenomenales borracheras, casi diarias, que cogían los parroquianos, a los cuales acompañaba a su casa, después de multar al tabernero ${ }^{36}$.

35 Esta prohibición era sistemáticamente incumplida, puesto que desde 1771, al menos, se colocaban los bandos cada seis meses en lugares públicos, sin conseguir la erradicación del juego.

36 El día 11 de abril escribe este párrafo: "Habiéndome encontrado en Mesón de Paredes a un sacerdote que iba dáncłose por las paredes y a quien los muchachos iban insultando, procuré amedrentarlos, y al sacerdote lo entré en una casa, donde se le dio 
En el trato de amos y criados respeta siempre las categorias sociales, estableciendo por principio inconmovible que las criadas adebian tener respeto a sus amos, como quien sirve a Dios en ellos». A una pobre chica que servia en una casa desde los diez años y que se habia escapado por no poder aguantar más a la señora, la reprende severamente diciéndola que, en caso de no sujetarse a obediencia, la recluiría en el hospicio. A otra le indica que no puede irse de la casa donde servia, acontra la voluntad de sus amosn. En el pleito de Rafaela Ramos, que reclamaba su salario y el dueño se lo negaba, acusándola de ladrona, escribe: "di una buena fraterna a la Rafaela, obligándola a pedir perdón al amon.

Si el estudio de este precioso documento nos sirve para descorrer el velo de la baja sociedad madrileña del XVIII, aún nos falta por descubrir una de las lacras morales más lamativas de este pueblo, inculto y arro* gente: me refiero a las relaciones conyugales. La instituciỏn matrimonial, por más que predicaran curas y frailes, estaba en crisis permanente, dado el carảeter altanero y sin escrúpulos de la mayoría de los parroquianos. En todo interviene uuestro alcalde, intentando apaciguar los ánimos, componer familias maltrechas y minimizar las ofensas mutuas, con un espiritu de concordia realmente ejemplar, que, a veces, lo situaban más cerca de la mansedumbre evangélica que de la justicia municipal.

Comencemos por decir que la simple organización de un baile familiar habia de contar con el permiso del alcalde, que limitaba el horario y el número de personas, a tenor de la vivienda donde se celebraba. La afición popular por los bailes, tan certeramente reflejada en los sainetes de la época, era tal que, con frecuencia, la aglomeración de gente deseosa del rítmico meneo se extendía por escaleras, pasillos, patios y galerias. Si había discusiones y altereados, alli se presentaba el alcalde para dar por terminada la fiesta, que, en todo easo, no podía prolongarse más allá de las once de la noche.

Aunque escape a su jurisdicción, no deja de anotar en el diario los hechos que presencia y que merecen su reprobación. Asi, anota un domingo de junio: «En los portales que llaman de Santa Cruz, y van a la Plaza Mayor, todos los días de fiesta, por mañana y tarde, concurren a ellos infinitos menestrales, que allí se paran, impidiendo el paso a las gentes que

una taza de té, vomitó y se serenó, y desde las cuatro hasta las ocho estuve acompañándole, sacándole después de bien anochecido para evitar todo escándalo, y por no haber querido decir quien era ni donde vivía, le dejé en la Fuente de Relatoresn. 
por ellos transitan, provocando a las mujeres, llamándolas garroteras, mozuelas y otros dicharachos, con los cuales atraen a sí infinitas criadas de servicio, que, o bien citadas, por casualidad u otros accidentes, pasan a oír misa a Santa Cruz, con los hijos e hijas de sus amos, que, confiados de su conducta, envian con ellas y las acompañan, de que indispensablemente se siguen notorios perjuicios a la buena educación, a más de los patentes escándalos que es público se cometen».

Iniciadas las relaciones de noviazgo, el alealde interviene para que se cumpla la palahra dada, prohilsiendo la cohabitación hasta que se celebre el matrimonio. Incluso. amonesta severamente a una madre por dejar entrar en la casa al novio antes de los esponsales. a La apercibi severamente - escribe en cierta ocasión - no dejase entrar al novio hasta obtener las bendiciones de la Iglesia, mnnilestando a todos estar por ello exeomulgados», En otra ocasión obliga a casarse a una pareja de amancebados, que vivian así «a sabiendas de que estaban en pecado mortals. Y cuando, por la denuncia de unos veciuos, coge ain fragantio a la pareja, êl da con sus huesos en la cárcel y ella en la galera de mujeres.

Si una madre va a quejarse de que un vecino rijoso llama todos los días a su hija para que vaya a peinarlo, con peligro de su honra, acude solícito el alcalde, le hace ver su inmoralidad y le prohibe que continúe con esa costumbre. Si una mujer acusa al marido de abandono del hogar, no ceja hasta dar con él y hacerlo volver a casa. Si un mozo es acusado de violar a una muchacha de dieciséis años, lo entrega a la justicia superior. Atiende, incluso, las reclamaciones de los presos que denuncian la vida licenciosa de su mujer mientras él está entre rejas.

Por su parte, las mujeres del barrio van a lamentarse continuamente de la (mala vida» que les da el marido, mostrándole con desenvoltura los moratones y cardenales que les causan en todas las partes del cuerpo. A todos ellos amonesta sentenciosamente, sentando el principio de que «su mujer no es ni su criada, ni su esclava, y que no tenían facultad para castigarla, y que era meramente una compañera y su prójimo más inmediato, a quien debía estimar y querer según se previene en el primer mandamiento". Al pocero Eugenio Arévalo, acusado de emplear armas contundentes con su mujer, le ordena que «no se tome la justicia por su mano, por estar absolutamente prohibido». De José Hernández, alias “el Rubio», que había amenazado con matar a su mujer, escribe que era tan incorregible "que hasta con el precepto pascual no había cumplido».

La mujer de un zapatero de la calle de la Comadre le cuenta, entre 
lágrimas, que su marido, furioso, «no sólo había tirado el puchero, dejando a todos sin comer, escandalizando la casa y oficiales que tenía, sino que también le había echado a ella de casa». Fue a ver al temperamental zapatero y le espetó con duras palabras que «no era dueño ni amo de su mujer, y si su compañero social... que el matrimonio era un nudo indisoluble y que su mujer era el más verdadero e inmediato prójimo a quien debía tolerar y sufrir»).

Otros majos de semejante calaña, como los apodados «el Conejo» y «el Maligno», eran la pesadilla del barrio y del alcalde. A un latonero de la Casa de las Animas (calle de la Comadre) le previene que trate bien a su mujer, sin echarla de casa ni obligarla a dormir en el portal. Otro tanto había hecho un oficial de la Secretaria de Indias con su mujer, preñada ce varios meses. A tal extremo podia llegar la desavenencia conyugal que una vecina de Lavapiés, Antonia Fuentes, "la Pastora», declara con firmeza que prefiere vivir en la cárcel o reclusa en San Fernando antes que volver con su marido.

Pero no vayamos a creer que era éste el único "tirano» de la vida familiar. A veces, el sexo femenino podía superar en irascibilidad al masculino. Como aquella Teresa Cadenas, «la más brava mujer de la calle de la Comadre», que no se andaba con chiquitas y tenía en jaque a hembras y varones, sin importarle la edad ni la condición. A una pobre vieja, que se había atrevido a llamarla en público «bruja» y "alcahueta», la dejó moribunda a base de golpes y arañazos. Algunos maridos, acobardados por la fiereza de su media naranja, vienen también a presentar sus quejas al alcalde. Un albañil denuncia a su mujer por «haberle ultrajado de palabras y acciones, repelándole y tratándole mal». Otro marido, recién casado, que tuvo la mala ocurrencia de irse a vivir a casa de la novia, en el Corralón de las Escobas, huye despavorido con las manos sobre la cabeza, perseguido por los escobonazos de mujer y suegra.

A la mujer de un tal Juan de Lara la reprende por el mal trato que daba a su cónyuge, "habiéndola manifestado la superioridad del marido y que debía vivir obediente a lo que mandare». Al dueño de una tienda de chocolate de la calle Ancha de Lavapiés, quejoso también de su mujer, le reconviene en su presencia por espacio de más de una hora, dejándoles convencidos de la obligación que tenían de tolerarse y sufrirse. Tampoco son infrecuentes los abandonos del hogar conyugal por parte de la mujer. Cuando la encuentra, como en el caso de la mujer de un zapatero, que se lleva todo el ajuar de la casa, abandonando no sólo al marido sino también a una hija de ocho años, la conduce de inmediato a la cárcel. 
Las quejas de los vecinos solian hacerse oralmente, pero hay casos de denuncias por escrito, sobre todo en temas de moral pública. Así, la que presenta el 24 de julio don Pedro Escolano, persona a la que supongo distinta del escribano del mismo nombre, a juzgar por la mala ortografía y peor estilo de letra. Dice asi: “Madrid, 24 de julio 91. Señor alcalde del barrio: No puede ser menos acerle sabedor la pieardía que anda en casa de una biuda en la calle de Jesús y María n. ${ }^{\circ}$ I, más abajo de la casa de Canosa con una güéspeda que tiene arecogida, pues está toda la bicinda[d] opuesta con esa muger. Le suprico a Vmd. que se ynforme de todos los becinos, de lo contrario lo tomaremos por nuestra mano. Mande Vmd. a serbidor, calle de las Carnetas n. 18. Dn. Pedro Escolano. A esta la lla-
ma[n] Ysabel».

Temido por su rectitud era don Pedro García, pero, al mismo tiempo, odiado y aborrecido por los valentones del barrio, que no le ahorraban desplantes e insultos. Todo lo sufría con paciencia, sostenido en la fuerza de la ley y en el apoyo de su Alcaldie de Cuartel, que lo era entonces don Clemente Alonso de Aróstegui. A estas virtudes de energía y prudencia se unía su total dedicación al duro menester de vigilancia y justicia, ya que para el alcalde de barrio no existían vacaciones. No digo ya veraniegas o pascuales. Ni un solo día del año, sea laborable o festivo, deja de anotar algo en su diario, aunque sólo fuese la ausencia de sucesos dignos de mención. Y en pago de tan abnegada conducta no recibió la más pequeña recompensa. La única aspiración de su vida, un puesio de funcionario en la Comisaría de Guerra, le fue denegada en tres ocasiones consecutivas.

Pero, dejando aparte anécdotas personales, ¿qué significación puede tener, en su conjunto, la vida reflejada en este ingenuo diario de un pequeño barrio madrileño en 1791 ? España vive temerosa por las consecuencias de la revolución francesa, y el gobierno cierra filas en torno a su consentidor monarca, que ve más peligra en un pueblo libre y bien informado que en la irresistible ascensión política del joven extremeño Manuel de Godoy, que, al año siguiente, por motivos inconfesables, sustituye al conde de Aranda en la Secretaría de Estado. Desaparecen de la escena política Floridablanca y Jovellanos, mientras el país se va hundiendo a marchas forzadas en la corrupción y el descontento popular. ¿Quién se entera de que el 16 de diciembre del año anterior el médico Francisco Salvá y Campillo había expuesto en la Academia de Ciencias de Barcelona un sistema de telegrafia eléctrica que superaba todo lo conocido entonces en Europa? Eso sí, la Santa Inquisición se había preocupado de prohibir ese mismo año el Tratado sobre 
La tolerancia de Voltaire, varias novelas francesas y el libro de Adam Smith, llamado a revolucionar la teoría económica.

Pero los vecinos de la Comadne nada saben de esto. Los limites de su experiencia vital están comprendidos entre la fuente de Relatores y la fuente de Lavapiés. A lo sumo, se han enterado de que en el verano anterior se había estrenado en el Teatro del Príncipe El viejo y la niña de Moratín, y en marzo de este año el Guzmán el Bueno de Iriarte; de que Goya, un famoso pintor palaciego, había reflejado sus costumbres en algunos dibujos para tapices, y que en el mes de agosto pasado un horroroso incendio había destruido parte de la Plaza Mayor.

Cierto es que tampoco hallaban modelos de vida ejemplar en otros niveles sociales. Sólo veían por doquier la vanidad de los nobles, la afectada elegancia de los abates, el afeminamiento de los petimetres, el descaro de los cortejos, la presuntuosa frivolidad de las damas, el escaso interés, en suma, de la sociedad toda por los bienes del espíritu. No faltaban, también es cierto, hombres íntegros como el alcalde don Pedro, pero eran los menos y no podían constituir la tónica general de la sociedad.

No vayamos, pues, a caer en el tópico de que el siglo de la Ilustración es el gran siglo de la Cultura. No podemos pasar por alto, desde luego, las grandes conquistas de largo alcance, saboreadas y valoradas solamente por una minoría elitista. Al pueblo llano apenas llegan los beneficiosos efectos del progreso intelectual. Para ellos no existe Ilustración. Sólo despotismo ilustrado.

Francisco Aguilar Piñal 